\title{
EARTH OBSERVATIONS FOR AGRICULTURAL MONITORING: EDITORIAL
}

\author{
Shibendu S Ray ${ }^{1}$, Ranganath Navalgund ${ }^{2}$ and Chris Justice ${ }^{3}$ \\ ${ }^{1}$ Mahalanobis National Crop Forecast Centre, India- shibendu.ncfe@nic.in \\ ${ }^{2}$ Indian Space Research Organisation, India- navalrr@gmail.com \\ ${ }^{3}$ University of Maryland, USA - cjustice@umd.edu
}

Earth observation data obtained from spaceborne, aerial and other platforms at different spectral regions and time intervals and spatial detail has immensely helped in inventorying, monitoring and condition assessment of agricultural resources. EO data available from a host of international space missions in both optical and microwave regions are being operationally used in many counties to make preharvest production forecasts and in assessing the impact of drought. Thus, EO techniques are proving to be important tools contributing to improve food security and meet the needs of UN Sustainable Development Goals. However, there are many scientific challenges in the application of EO data in the assessment of minor, short duration crops grown in fragmented land holdings, non-paddy crops grown during kharif season (cloud covered periods), in more precise productivity estimation, in estimating the impact of extreme weather on production, in early detection of disease affected crops etc. Newer techniques of data fusion, use of hyperspectral data and machine learning tools are advancing the use of EO data. In this context, the Group on Earth Observations, an international forum has initiated a programme on Global Agricultural Monitoring (GEOGLAM), in which many coordinated efforts are successfully being undertaken for the use of EO data. In order to review the progress made, challenges faced and to advance this initiative, a joint international workshop was organised by the International Society for Photogrammetery and Remote Sensing (ISPRS) Working Group III/10 (Agriculture and Natural Ecosystems Modelling and Monitoring), the Indian Society of Remote Sensing and GEOGLAM at the Indian Agricultural Research Institute in New Delhi, India during February 18-20, 2019. More than one hundred research articles were received for oral and poster presentations at this workshop. The manuscripts deal with the application of EO data for production forecasts of different crops grown under irrigated and dryland conditions, the impact of likely climate change on crop yield, extreme weather and agriculture, use of EO data in crop intensification, retrieval of biophysical parameters from EO data for further use in process models, use of microwave SAR and scatterometer data in estimating crop parameters, detection of wheat blast, water use efficiency, and so on. There were several presentations dealing with development of advanced techniques for data analysis etc. The current volume is a collection of all the manuscripts presented at the workshop. All the papers have gone through a preliminary review and editing. We do hope, this volume will provide material for all those professionals and decision/policy makers interested in the applications of EO data for agricultural monitoring. 